\title{
Human immunodeficiency virus among people who inject drugs: Is risk increasing in Europe?
}

\author{
D Hedrich (dagmar.hedrich@emcdda.europa.eu) ${ }^{1}$, E Kalamara ${ }^{1}, 0$ Sfetcu², A Pharris ${ }^{2}$, A Noor ${ }^{1}$, L Wiessing ${ }^{1}$, V Hope², \\ M Van de Laar ${ }^{2}$ \\ 1. European Monitoring Centre for Drugs and Drug Addiction (EMCDDA), Lisbon, Portugal \\ 2. European Centre for Disease Prevention and Control (ECDC), Stockholm, Sweden \\ 3. Centre for Infectious Disease Surveillance and Control, Public Health England, London, United Kingdom
}

In most European Union (EU)/European Economic Area (EEA) countries, between 2010 and 2012, reports of new human immunodeficiency virus (HIV) diagnoses among people who inject drugs have been stable or declining. HIV outbreaks in Greece and Romania, first reported in 2011, continue and economic conditions hinder provision of effective response coverage. When measured against some established thresholds, prevention coverage remains inadequate in at least onethird of EU/EEA countries. Urgent consideration to scale up prevention efforts is merited.

\section{Introduction}

In response to sharp increases in human immunodeficiency virus (HIV) notifications reported among people who inject drugs (PWID) in Greece and Romania, a risk assessment of HIV transmission among PWID was carried out in the European Union/European Economic Area (EU/EEA), Croatia and Turkey, in 2011. The report, covering 31 countries, confirmed outbreaks among PWID in Greece and Romania and noted a potential for outbreaks elsewhere $[1,2]$. This update, based on a survey conducted in mid-2013, summarises developments in HIV transmission and injecting risks among PWID since 2010 and identifies areas where scale-up of evidence-based preventive measures is needed to avoid further outbreaks.

\section{Data collection for indicators and analysis}

This study analysed multiple sources of disease and prevention service data for the period 2010 to 2012 collected from 31 countries, including 27 EU Member States, Croatia, two EEA countries (Iceland and Norway) as well as Turkey. The data were provided through the regular monitoring systems of the European Monitoring Centre for Drugs and Drug Addiction (EMCDDA) and the European Centre for Disease Prevention and Control $(E C D C)$. These data were augmented with a rapid enquiry of their respective expert networks in MayJune 2013. The enquiry used an excel table pre-filled with data previously reported for 2010 and 2011 for purposes of validation or correction. The table also served as a survey tool to report 2012 data. The data of interest focused on three groups of indicators, as well as on questions regarding HIV prevention funding, such as if this funding was adequate, if it had changed between 2010 and 2012 and if changes were expected in the coming two years.

The three groups of indicators analysed for the period between 2010 and 2012 comprised the following: (i) HIV trend: data on HIV case reports with injecting drug use as mode of transmission for the period from 2010 to 2012 notified to ECDC through the European Surveillance System (TESSy) were analysed alongside data on HIV prevalence among PWID, (ii) transmission risk: data on prevalence of injecting drug use trends, changes in injecting risk behaviour, and trends in hepatitis $\mathrm{C}$ virus (HCV) prevalence, and (iii) data on prevention service coverage routinely reported to the EMCDDA $[3,4]$, including opioid substitution treatment (OST) and needle and syringe programmes (NSP) coverage.

For each country, the first two indicators were characterised either as 'no alert', 'concern' or 'alert'. As the classification of levels of NSP and OST coverage is based on established thresholds, the third indicator could only be qualified as 'alert' or 'no alert'.

HIV trend in the countries was classified under 'alert' if there was a significant ( $p<0.05$ ) increase in HIV case reports or prevalence between 2010 and 2012. Classification as 'concern' was assigned if there was a significant increasing trend in HIV prevalence at subnational level (e.g. in a city or a region) during the same period or a consistent but non-significant rise in HIV cases at national level. 'No concern' indicated that there was no evidence of increasing HIV cases or prevalence in a country.

Risk for increased HIV transmission was characterised as an 'alert' if any of the following conditions were reported through national drug focal points or reporting systems: increased or high ( $\left.{ }_{5} 50 \%\right) \mathrm{HCV}$ prevalence 
among PWID; increased prevalence of injecting drug use; or changes in drug use patterns such as increased stimulant injection. A 'concern' was defined as a subnational increase. There was 'no alert' when no evidence of increases occurred with regard to HCV prevalence, prevalence of injecting drug use, and stimulant injection among PWID.

Prevention service coverage was classified as 'alert' if the proportion of problem opioid users receiving OST (OST coverage) was less than 30\% and/or if the annual average number of syringes distributed by NSPs per PWID (NSP coverage) was less than 100/PWID/year.

All data reported were validated by national HIV surveillance and national drug focal points to ensure that the most recent available data were included.

\section{Results}

Characteristics of each of the indicators considered in this study, by country, are shown in the Table.

Human immunodeficiency virus case reports and prevalence among people who inject drugs Except for Liechtenstein, which did not take part in the risk assessment, data on HIV diagnoses with injecting drug use as the mode of transmission from 2010 to 2012 were provided by all EU/EEA countries, as well as by Croatia and Turkey. Information on HIV prevalence among PWID during the period from 2010 to 2012 was given by 26 countries, eight of which (Belgium, Bulgaria, Estonia, Germany, Lithuania, Netherlands, Sweden and the United Kingdom) only had subnational data. No data on HIV prevalence among PWID were available from Croatia, Denmark, Finland, Iceland and Ireland.

Twenty-five countries reported stable or declining population rates of HIV diagnoses in PWID over the past three years, continuing the trend observed throughout much of the EU/EEA from the mid-2000s [5]. In 2012, rates of new HIV diagnoses associated with injecting drug use were below 1.0 per 100,000 population for 26 countries, between 1.0 and below 4.0 for Romania and Lithuania and above 4.0 for Greece, Latvia and Estonia (Figure).

Greece and Romania report ongoing outbreaks [6-9] leading to an almost 20 -fold increase in new diagnoses among PWID between 2010 and 2012. Taken together, these two countries reported more than one third of the HIV diagnoses associated with injecting drug use in the 31 countries in 2012, compared to only $2.2 \%$ in 2010. These outbreaks are concentrated in the capital cities, with reported HIV prevalence among PWID in Athens of $20 \%$ [10] and Bucharest of $53 \%$ [9].

In Austria, Bulgaria, Estonia and Latvia, the extent to which the recent evolution in HIV trends represents a significant risk is unclear. In Estonia and Latvia, after major HIV outbreaks between the late 1990 s and the early 2000 s leading to high prevalence [11,12], new HIV case reports declined until 2008 in Estonia and until 2009 in Latvia [5], but incidence remains high in 2012 ( $34 / 100,000$ population) (Figure). Between 2010 and 2012, HIV diagnoses have slightly risen in both countries, while HIV prevalence studies among PWID in Latvia (national level: $20.2 \%$ ) and Estonia (KothlaJarve: $61.8 \%$ ) showed high levels of HIV. In Austria, the number of HIV diagnoses rose slightly over the period between 2010 and 2012 and HIV prevalence among PWID at low-threshold facilities in Vienna increased fivefold from $0.8 \%$ in 2010 to $4.9 \%$ in 2012. In Bulgaria, HIV diagnoses fluctuated at national level, but a doubling of prevalence of HIV among young PWID in Sofia from $3.1 \%$ in 2010 to $6.1 \%$ in 2011 was noted (Table).

\section{Human immunodeficiency}

virus transmission risk

Trends in HCV prevalence among PWID are an indicator of injecting risk and high HCV prevalence can be a proxy for HIV transmission risk [13]. In 2012, increases in HCV or very high prevalence of HCV among PWID $(50-80 \%)$ were reported in nine countries: Belgium (Flemish community), Bulgaria (Sofia), Cyprus, Estonia (Narva), Greece, Italy (several regions), Latvia, Romania (Bucharest), and Turkey.

Increased injecting of stimulants was reported in four countries. In Romania and Hungary, this reflected the appearance of new stimulant drugs on the market, such as cathinones, leading to more frequent injecting among traditional opiate users [14]. Austria and Greece previously reported increases in methamphetamine injecting [1]. However in Athens, Greece, opiates continue to be the main drug of use.

\section{Prevention coverage and funding}

Data on prevention coverage were available for 25 countries (OST: 20; NSP: 13) (Table). Most countries have implemented relatively high levels of prevention services, but 10 countries report low prevention coverage, either for OST ( 6 countries with coverage ranging from 4 to $20 \%$ ) or for NSP (7 countries report distributing less than 100 needles and syringes/PWID/year, including Turkey where NSP is not available).

In Greece, scale-up of prevention coverage from low activity started in 2011 [15]; this has been impeded by financial constraints since late 2012 [16]. In Romania, coverage has reduced substantially since 2010 , when a Global Fund grant ended, with the rate of 47 syringes per PWID reported (Bucharest, 2012) far below estimated need [6] and OST remains limited. Since July 2013 the main harm reduction provider (Romanian AntiAIDS Association, ARAS) had to halve services [17] due to limited resources. In Bulgaria, a Global Fund grant will end in 2014.

\section{Discussion}

The previous assessment, carried out in 2011 identified worrying spread of HIV among PWID in Greece 

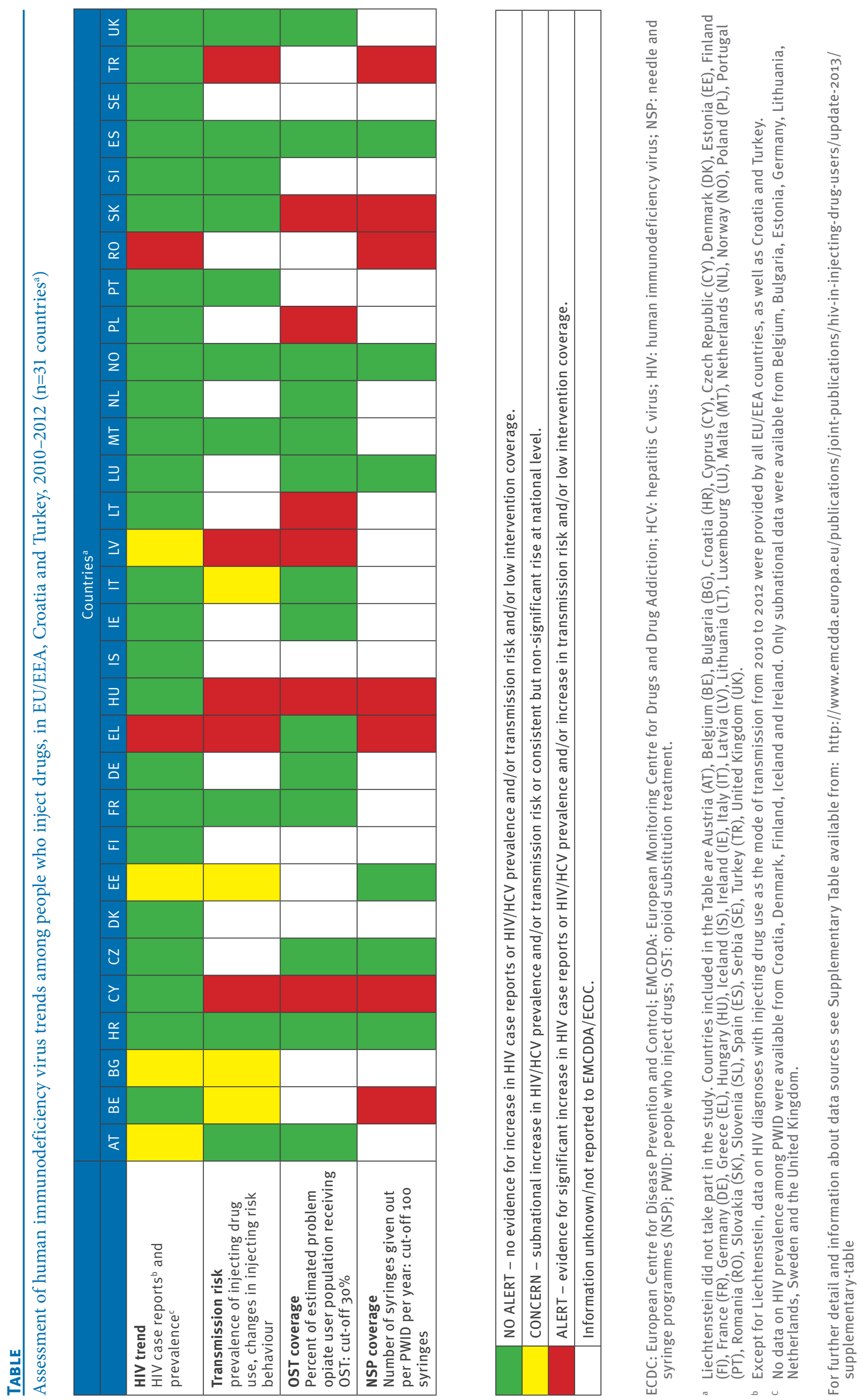
Rates of newly diagnosed human immunodeficiency virus (HIV) infections with injecting drug use as mode of transmission in EU/EEA, Croatia and Turkey, 2012 ( $n=32$ countries)
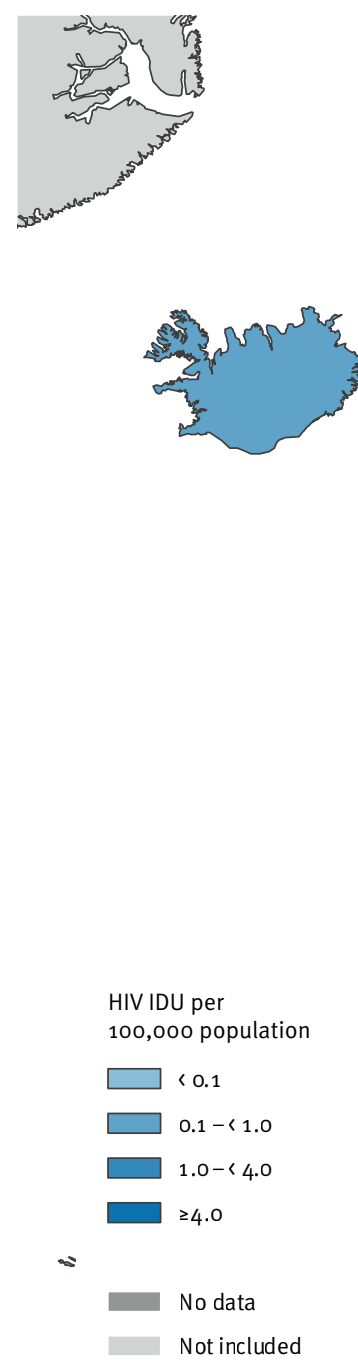

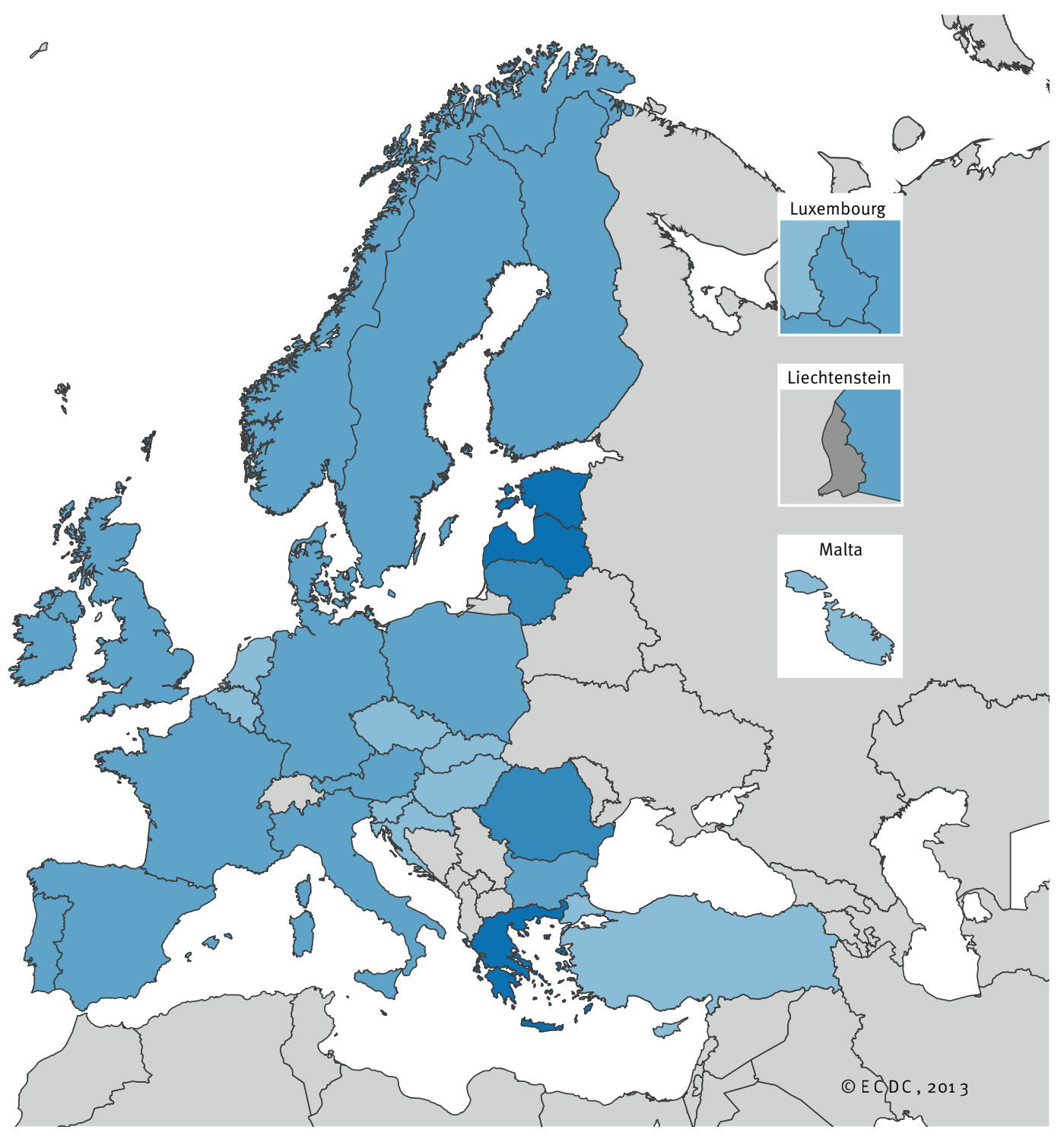

EEA: European Economic Area; EU: European Union; HIV IDU: HIV infections with injecting drug use as mode of transmission.

and Romania [1,2]. This updated assessment confirms these continuing and serious outbreaks and also provides the most recent data on trends in HIV among PWID in the EU/EEA region as a whole. It is based on a considerable amount of hitherto unpublished data on drug-related indicators, which were gathered through a rapid inquiry in May-June 2013.

Apart from Greece and Romania, HIV among PWID appears to be stable or declining in much of the EU/ EEA. However, in at least eight other countries, data suggests that substantial populations of PWID have limited access to OST and NSP services and may therefore be vulnerable with regard to outbreaks in the future.

Vigilance is required where indicators of potential risk for increased HIV transmission, such as increases in HCV infection, high HCV prevalence, and increased stimulant injecting are reported. Increased injection of stimulants poses challenges for prevention services, requiring increased NSP provision to cover more frequent injecting and more emphasis on active outreach. Recent reports of increased injecting of cathinones leading to an HIV outbreak among PWID in Israel underline this [18]. Increased reported stimulant use also implies that greater attention be paid to 
sexual transmission among PWID. In London a possible increase in stimulant injection among men who have sex with men (MSM) and subsequent increase in HIV transmission has been reported [19].

There are limitations to this assessment. Data on HIV notifications for $\mathbf{2 0 1 2}$ are liable to revision due to adjustment for reporting delays. For several countries, prevention coverage could not be estimated due to missing data or lack of a denominator. For example, coverage of OST could not be calculated for Belgium, Bulgaria, Denmark, Estonia, Finland, Iceland, Portugal, Romania, Slovenia, Sweden, and Turkey due to a lack of estimates of the prevalence of opiate use.

Effective control of HIV transmission among PWID requires a comprehensive public health policy including adequate provision of both NSP and effective treatment of drug dependence together with health promotion, accessible HIV testing, targeted service delivery, and antiretroviral treatment (ART) for HIV positive persons [20]. To avoid high long-term healthcare costs and preventable future morbidity and mortality, reaching and maintaining an adequate level of prevention is needed in all EU/EEA countries but most urgently in those identified as vulnerable to increases in HIV among PWID. In some cases, economic conditions and funding shortages threaten adequate responses.

\section{Acknowledgements}

The authors wish to thank all EMCDDA Reitox Focal Points and ECDC national HIV surveillance contact points who responded to the rapid request for information.

\section{Conflict of interest}

None declared.

\section{Authors' contributions}

Dagmar Hedrich, Otilia Sfetcu, Eleni Kalamara, Anastasia Pharris, Lucas Wiessing and André Noor designed the protocol for the rapid survey. Eleni Kalamara analysed the trends in drug-related datasets and Otilia Sfetcu the trends in HIV case reports. Dagmar Hedrich was the lead author. All authors reviewed and commented on the manuscript throughout its production.

\section{References}

1. European Monitoring Centre for Drugs and Drug Addiction (EMCDDA), European Centre for Disease Prevention and Control (ECDC). Joint EMCDDA and ECDC rapid risk assessment: HIV in Injecting Drug Users in the EU/EEA, following a reported increase of cases in Greece and Romania. Lisbon: EMCDDA; 2012. [Accessed 16 Sep 2013]. Available from: http:// www.emcdda.europa.eu/publications/joint-publications/ hiv-in-injecting-drug-users-2011

2. Pharris A, Wiessing L, Sfetcu O, Hedrich D, Botescu A, Fotiou $A$, et al. Human immunodeficiency virus in injecting drug users in Europe following a reported increase of cases in Greece and Romania, 2011. Euro Surveill. 2011;16(48):pii=20032. Available from: http://www.eurosurveillance.org/ViewArticle. aspx?Articleld $=20032$
3. European Monitoring Centre for Drugs and Drug Addiction (EMCDDA). Statistical Bulletin 2013. Lisbon: EMCDDA; [Accessed 16 Sep 2013]. Available from: http://www.emcdda. europa.eu/stats13

4. European Monitoring Centre for Drugs and Drug Addiction (EMCDDA). European Drugs Report 2013. Lisbon: EMCDDA; 2013. [Accessed 16 Sep 2013]. Available from: http://www.emcdda.europa.eu/publications/edr/ trends-developments/2013

5. European Centre for Disease Prevention and Control (ECDC)/ World Health Organization Regional Office for Europe. HIV/ AIDS surveillance in Europe 2012. Stockholm: ECDC; 2013. [Accessed 27 Nov 2013]. Available from: http://www.ecdc. europa.eu/en/publications/Publications/hiv-aids-surveillancereport-2012-20131127.pdf

6. Botescu A, Abagiu A, Mardarescu M, Ursan M. HIV/AIDS among injecting drug users in Romania. Report of a recent outbreak and initial response policies. Lisbon: European Monitoring Centre for Drugs and Drug Addiction; 2012. [Accessed 16 Sep 2013]. Available from: http://www.emcdda.europa.eu/ publications/ad-hoc/2012/romania-hiv-update

7. Fotiou A, Micha K, Paraskevis D, Terzidou M, Malliori M, Hatzakis A. HIV outbreak among injecting drug users in Greece. An Updated brief report for the EMCDDA on the recent outbreak of HIV infections among drug injectors in Greece, 31 October 2012. Lisbon: European Monitoring Centre for Drugs and Drug Addiction; 2012. [Accessed 16 Sep 2013]. Available from: http://www.emcdda.europa.eu/publications/ad-hoc/2012/ greece-hiv-update

8. University Mental Health Research Institute Athens / Greek Reitox Focal Point of the EMCDDA (2013). Follow-up on the risk assessment on HIV in Greece- Update on behavioural surveillance data and other estimates. Presentation at Ministry of Health; 3 June 2013; Athens. Restricted-access-document.

9. Abagiu A, Botescu A. Update on country situation: Romania. Presentation at 2 nd meeting on detecting and responding to outbreaks of HIV among people who inject drugs, Lisbon 12 October 2012. Lisbon: European Monitoring Centre for Drugs and Drug Addiction; 2012. [Accessed 16 Sep 2013]. Available from: http://www.emcdda.europa.eu/html.cfm/ index195202EN.html

10. Sypsa V, Paraskevis D, Malliori M, Nikolopoulos GK, Panopoulos T, Kantzanou M, et al. Homelessness and other risk factors for HIV infection in the current outbreak among injecting drug users in Athens, Greece. Am J Public Health. [forthcoming].

11. Ferdats A, Konicheva V, Dievberna I, Lilja E, Albert J. An HIV type 1 subtype A outbreak among injecting drug users in Latvia. AIDS Res Hum Retroviruses. 1999;15(16):1487-90. http://dx.doi.org/10.1089/088922299310007 PMid:10555112

12. Rüütel K, Uusküla A. HIV epidemic in Estonia in the third decade of the AIDS era. Scand J Infect Dis. 2006;38(3):181-6. http://dx.doi.org/10.1080/00365540500388743 PMid:16507499

13. Vickerman P, Hickman M, May M, Kretzschmar M, Wiessing L. Can hepatitis $C$ virus prevalence be used as a measure of injection-related human immunodeficiency virus risk in populations of injecting drug users? An ecological analysis. Addiction. 2010;105(2):311-8.

http://dx.doi.org/10.1111/j.1360-0443.2009.02759.x PMid:19922515

14. European Monitoring Centre for Drugs and Drug Addiction (EMCDDA), European Centre for Disease Prevention and Control (ECDC). Meeting report: 2nd meeting on detecting and responding to outbreaks of HIV among people who inject drugs, Lisbon 12 October 2012. Lisbon: EMCDDA; 2012. [Accessed 16 Sep 2013]. Available from: http://www.emcdda. europa.eu/html.cfm/index195202EN.html

15. Malliori M, Golna C, Souliotis K, Hatzakis A. Managing opioid dependence treatment and controlling for HIV incidence among injecting drug users in Greece: a case study of optimism in the face of adversity. Addiction.2013; 108(6): 1174-5. http://dx.doi.org/10.1111/add.12179 PMid:23659849

16. Update on response to the HIV/PWID epidemic, Micha, K. (Okana). Presentation at Ministry of Health; 3 June 2013; Athens. Restricted-access-document.

17. Agentia Nationala Antidrog Public Relations Department. Comunicat de presă privind problematica asistentei consumatorilor de droguri injectabile, 2 iulie 2013. [Press release on the issue of assistance to people who inject drugs. 2 July 2013]. Romanian. [Accessed 16 Sep 2013]. Available from: http://www.ana.gov.ro/stire126.php

18. Katchman E, Savyon M, Chemtob D, Avidor B, Mor O, Wasserman A et al. An outbreak of primary HIV infection among injecting drug users in Tel Aviv, Israel associated 
with changes in the illicit drug use practices. European AIDS

Conference (EACS); Brussels; 2013. Abstract PS11/4.

19. Gilbart VL, Simms I, Gobin M, Oliver I, Hughes G. High-

risk drug practices in men who have sex with men. Lancet. 2013; 381(9875):1358-9. http://dx.doi.org/10.1016/

So140-6736(13)60882-X

20. European Centre for Disease Prevention and Control (ECDC), European Monitoring Centre for Drugs and Drug Addiction (EMCDDA). Prevention and control of infectious diseases among people who inject drugs. Stockholm: ECDC; 2011.

[Accessed 16 Sep 2013]. Available from: http://www.emcdda. europa.eu/publications/ecdc-emcdda-guidance 